\title{
Obesidade entre os pobres no Brasil: a vulnerabilidade feminina
}

\author{
Obesity among the poor in Brazil: female vulnerability
}

Vanessa Alves Ferreira ${ }^{1}$

Rosana M agalhães ${ }^{2}$
Abstract The increase in obesity among women in the lower income bracket in Brazil has been singled out as a priority issuein the field of Public H ealth today. Concern about future repercussions of obesity in the less privileged groups calls for an in-depth theoretical approach and the energetic definition of public policy for prevention and control of the affliction in these segments. In this respect, the scope of this work is to attempt to pinpoint some analytical categories in the phenomenon of obesity among the underprivileged female population in Brazil. Biological, socioeconomic and cultural factors appear to interact in the dynamics of female obesity in the context of poverty revealing the complexity of this problem. Public policies of job creation, social inclusion and gender equality in the labor market would appear to be more promising ways of tackling obesity in underprivileged females in Brazil.

Key words O besity, Poverty, Women, Public policies
Resumo No Brasil, o incremento da obesidade em mulheres inseridas nos menores percentis de renda tem sido destacado como tema prioritário para o campo da Saúde Pública na atualidade. A preocupação com as repercussões futuras da obesidadenos grupos menos favorecidosimpõeo aprofundamento teórico e o delineamento de políticas públicas de prevenção e controle da enfermidade nesses segmentos. N essa perspectiva, este trabalho se propõe a discutir al gumas categorias analíticas presentes no fenômeno da obesidade entre a população pobre feminina no Brasil. Fatores biológicos, socioeconômicos e culturais parecem interagir na dinâmica da obesi dade feminina no contexto da pobreza, revelando a complexidade dessa problemática. Políticas públicas de geração de emprego, inclusão social e igualdade no mercado de trabalho entre os gêneros nos parecem caminhos mais promissores para o enfrentamento da obesidade entre mulheres pobres no país. Palavras-chave Obesidade, Pobreza, Mulheres, Políticas públicas
${ }^{1}$ Departamento deN utrição, Universidade Federal dos Vales do Jequitinhonhae M ucuri. Rua da Glória 187, Centro. 39100-000 Diamantina MG. vanessa.nutr@ig.com.br ${ }^{2}$ Escola Nacional de Saúde Pública Sergio Arouca, Fundação O swaldo Cruz. 
Introdução

0 incremento da obesidade em populações que vivem em situação de pobreza tem sido destacado recentemente pela literatura ${ }^{1-3}$. É notável a ascensão da obesidade em países em desenvolvimento tais como as sociedades latino-americanas ${ }^{2}$. Esses dados corroboram a desmistificação da ideia predominante de que os agravos relacionados à subnutrição têm maior impacto nos países em desenvolvimento. E que os problemas alimentares associados ao excesso dietético predominam entre os países desenvolvidos. Tal fato se aproxima da ideia em consolidação de que os países em desenvolvimento tendem a passar dos seus padrões de saúde "antigos" para os padrões negativos dos países ditos desenvolvidos, não sendo beneficiados com a experiência antecipada destes.

No Brasil, a realização de consecutivosinqué ritos nutricionais de âmbito nacional ao longo das últimas décadas permitiu analisar a magnitude da obesidade no Brasil, bem como mapear o comportamento da enfermidade. A comparação dos resultados provenientes do Estudo $\mathrm{Na}$ cional de Despesa Familiar (Endef) realizado entre os anos de 1974 e 1975; da Pesquisa Nacional de Saúde e Nutrição (PNSN), de 1989; e da Pesquisa de Orçamentos Familiares (POF) desenvolvida nos anos de 2002 e 2003 permite verificar a tendência da evolução do excesso de peso no país. Em 1975, a prevalência da obesidade na população adulta era de 5,7\%. A pesquisa realizada em 1989 revelou um percentual quase duas vezes maior da prevalência encontrada na década de 70: 9,6\%. Mais recentemente, os dados da POF 2002-2003 confirmaram esse perfil de crescimento em que os valores atingiram pouco mais de $11 \%{ }^{4}$. Em linhas gerais, a pesquisa evidenciou um padrão de evolução do excesso de peso para o país como um todo. 0 problema alcança enorme expressão em todas as regiões brasileiras, no meio urbano eno rural, e ainda em todas as classes de rendimentos 4 .

Diferenças no comportamento do excesso de peso entre os sexos, contudo, são evidenciadas. Nos homens, a prevalência do excesso de peso apresenta comportamento linear para todas as regiões, sendo mais prevalente nas regiões Sudeste $(9,8 \%)$, Sul $(9,7 \%)$ e Centro-O este $(8,4 \%)$, respectivamente ${ }^{4}$. A obesidade afeta $8,9 \%$ da população masculina no país. Na pesquisa, observa-se ainda que entre os homens a frequência da obesidade aumenta de modo uniforme e intenso com a renda, sendo mais prevalente entre os indivíduos situados nos estratos de maior renda4.
No caso da população feminina, a ascensão da obesidade é verificada no período entre os dois primeiros inquéritos (1974/75-1989), em que as prevalências passaram de $7,8 \%$ para $12,8 \%$. No segundo período (1989-2002/2003), a prevalência evolui apenas no grupo de mulheres residentes da Região N ordeste: 9,0\% para $11,5 \%$. E ainda entre os estratos de menor rendimento, mais especificamente restrito às duas primeiras classes de renda. Na primeira classe, a prevalência de obesidade entre mulheres evolui de 9,7\% para $11,8 \%$, enquanto na segunda classe passou de $10,7 \%$ para $13,7 \%$. N ota-se que o comportamento da obesidade no grupo feminino nas demais regiões e estratos de maior rendimento se estabelece ou mesmo declina no período 4 .

A pesquisa concluiu que a obesidade global avança na população adulta brasileira eapresenta impacto importante nos segmentos menos favorecidos ${ }^{4}$. N esse contexto, observa-se a vulnerabilidade do grupo feminino à dinâmica da obesidade no contexto de exclusão e pobreza 5 . Assim, de acordo com a pesquisa, no período mais recente, o problema do excesso de peso em mulhe res tende a se deslocar para a região nordeste e, de modo geral, para as classes de menor renda 4 .

A partir do exposto, é possível constatar que a obesidade feminina hoje no Brasil circunscreve-se na região de menor desenvolvimento do país - o Nordeste brasileiro. E ainda nos segmentos mais desfavorecidos economicamente. Este perfil evidencia o deslocamento da obesidade para o contexto de exclusão social do país revelando a conformação de um panorama alimentar desigual. $\mathrm{O}$ N ordeste brasileiro ainda se configura como uma região deintensas desigualdades sociais. De acordo com a Pesquisa Nacional de Amostra Domiciliar do Instituto Brasileiro de Geografia e Estatística (PNAD/IBGE) ${ }^{5}$ realizada em 2006, permanecem as desigual dades no acesso a bens e serviços entre as regiões brasileiras, com um impacto desfavorável para a Região N ordeste. Nesta região, 79,5\% dos domicílios têm coleta de lixo, e o acesso ao saneamento básico atende apenas $40,4 \%$ das moradias. Com relação ao acesso a equipamentos no domicílio, somente $33,8 \%$ dos lares nordestinos têm tel efone e $81,3 \%$ dispõem de geladeira ${ }^{5}$. No que diz respeito à educação, verificou-se que a taxa de "analfabetismo funcional" foi maior nessa região (36,6\%) quando comparada com a Região Sudeste $(17,5 \%)$ do país 5 . É nessa região que se localizam ainda metade dos indivíduos que se encontram abaixo da linha de miséria (LM), ou seja, que não dispõem de renda suficiente para 
obtenção da cesta alimentar mínima. No que se refere à renda, observou-se que os trabalhadores nordestinos continuam a receber em média os menores rendimentos do país $(\mathrm{R} \$ 490,40)^{5}$. 0 rendimento médio mensal para o país em 2006, de acordo com a PNAD, foi de $R \$ 808,80$.

Dessa maneira, a ascensão da obesidade nessa região impõe aprofundar a discussão acerca de novas abordagens teórico-metodológicas sobre sua dinâmica, que de alguma forma possam subsidiar o planejamento de políticas públicas de equidade em saúde especificamente, ações no campo da promoção da saúde, prevenção e controle da enfermidade. Reconhecendo quetaisgrupos não dispõem dos principais recursos para a prevenção e o controle da obesidade, esse debate mostra-se pertinente e atual para o campo da nutrição e da Saúde Coletiva, suscitando novos desdobramentos e proposições sobre o tema em questão. N essa direção, este trabal ho busca realizar uma análise crítica de diferentes questões que, de forma interconectada, podem estar contribuindo para o atual panorama da obesidade entre mulheres brasileiras, especialmente as que vivem em condições de pobreza.

\section{Metodologia}

Este trabalho faz parte dos resultados de uma pesquisa realizada na Escola Nacional de Saúde Pública Sergio Arouca, da Fundação Oswaldo Cruz (Ensp/Fiocruz), no curso de mestrado, sobre a relação entre obesi dade e pobreza entre os anos de 2001 e $2003^{6}$. A revisão de literatura foi atualizada e foi feita a partir da busca ativa de informações nas bases de dados do Centro Latino-Americano e do Caribe de Informações em Ciências da Saúde (Bireme), M edlinee Lilacs, assim como da biblioteca virtual SciELO ede bibliotecas especializadas, incluindo as localizadas no Instituto de Pesquisa Econômica Aplicada (Ipea/ RJ), Fundação Getúlio Vargas (FGV/RJ), M useu Nacional (UFRJ) eEnsp/Fiocruz. Buscou-serealizar a pesquisa bibliográfica sobre os dois temas centrais da pesquisa: obesidade e pobreza. Importante ressaltar que a análise realizada se apoia em estudos científicosque discutem a questão do gênero, por distintos percursos teóricometodológicos.

Partimos da ideia central de quetanto a obesidadequanto a pobreza sereferem a conceitoscomplexos e multifacetados. N esse sentido, optamos por real izar uma investigação em uma perspectiva analítica mais ampla, objetivando superar pos- síveis fragmentações e dicotomias. Dessa maneira, a pesquisa incorporou categorias analíticas distintas dentro de quatro eixos temáticos investigativos: biológico, socioeconômico, simbólico-cultural e emocional. No primeiro eixo, o "bio-lógico", discutiremos questões referentes aos diferenciais da gordura corporal entre os sexos e os fatores ontológicos relacionados às estratégias biológicas e adaptativas. No segundo eixo, 0 "socioeconômico", abordaremos uma gama de indicadores sociais (educação, trabalho, renda, raça, arranjos familiares) eainda elementos associados ao estilo de vida, incluindo a dieta e a atividade física. No terceiro eixo, iremos nos deter no universo simbólico relacionado às dimensões da alimentação e do corpo. Por fim, no último eixo iremos privilegiar a interferência do aspecto emocional nos hábitos e práticas alimentares do grupo.

\section{O "bio-lógico"}

Sob o prisma biológico, já está bem reconhecida a distinção da gordura corporal entre os sexos. 0 percentual de gordura corpórea é relativamente maior nas mulheres do que entre os homens ${ }^{7}$. De acordo com a literatura, a concentração maior de gordura feminina relaciona-seà reprodução, em razão da maior necessidade de energia nos períodos biológicos da gravidez e da lactação. No Brasil, al guns estudos têm demonstrado a relação positiva entre o agravo da obesidade e os fatores obstétricos ${ }^{8,9}$. O utras investigações têm pautado suas hipóteses nos fatores ontogênicos ${ }^{10,11}$. Tais trabalhos pressupõem que indivíduos pobres que sofreram situações de má nutrição durante 0 desenvolvimento fetal ou mesmo na infância tendem a desenvolver mecanismos de adaptação metabólica. A situação de insuficiência al imentar pregressa geraria formas adaptativas de sobrevivência. Essa estratégia biológica tenderia a preservar energia através de um baixo metabolismo, o que, por sua vez, favoreceria 0 armazenamento de gordura e consequentemente 0 desenvolvimento da obesidade numa idade mais avançada. Assim, pobres rurais com história de desnutrição na infância, ao se deslocarem para a área urbana emelhorar suas condições nutricionais, tenderiam a desenvolver a obesidade ${ }^{10}$. Essa hipótese, associada à maior predisposição feminina ao acúmulo de gordura corporal, poderia explicar a frequência da obesidade entre mulheres pobres no Brasil. No entanto, ainda não existe consenso acerca dessa hipótese muito em razão da frequência de estudos pouco conclusivos sobre o tema ${ }^{11}$. 
Indicadores sociais e o estilo de vida

Aspectos sociais relacionados ao nível de escolaridade também parecem estar presentes na prevalência el evada deobesidade no grupo feminino de baixa renda. Monteiro et al. ${ }^{12}$ observaram a associação positiva entre baixa escolaridade e obesidade entre mulheres com base em inquéritos realizados no período de 1974 a 1997 nas regiões Sudeste e N ordeste do país. Os autores constataram a maior exposição à obesidade entre mulheres de menor nível de escolaridade. Nessa mesma direção, Kac et al. ${ }^{13}$ verificaram em seu estudo que quanto menor era a escolaridade feminina, maior era a relação cintura/quadril (RCQ) do grupo investigado.

A respeito da relação entre nível educacional e cuidados com o corpo, Boltanski ${ }^{14}$ sinaliza que a preocupação que os sujeitos depositam sobre o corpo cresce com a hierarquia social. Essas ações, segundo o autor, podem ser explicadas pela relação mais reflexiva com o corpo por parte dos segmentos de mais alta renda, em razão do melhor nível educacional e da maior inserção desses grupos em ocupações de cunho intelectual. Além disso, para Sobal1 ${ }^{15}$, a condição material de vida do grupo permite 0 acesso a alimentos mais apropriados para a manutenção da saúde. Nessa direção, de acordo com Peña e Bacallao², as limitações de oportunidades combinadas à desvalorização social do corpo feminino explicariam as prevalências mais el evadas de obesidade entre as mulheres das classes populares. Nessa perspectiva, observam-se nos últimos anos no Brasil mudanças socioeconômicas importantes para o grupo feminino. As mulheres atualmente representam um dos subgrupos mais vulneráveis ao estado de pauperização no país. As pesquisas nacionais $5^{16-19}$ demonstram que 0 grupo feminino tem sofrido impactos estruturais importantes no contexto do trabalho, na esfera social e, ainda, no âmbito familiar.

A análise das condições detrabalho do grupo feminino no Brasil mostra avanços e retrocessos. Dessa forma, os indicadores revelam a evolução do número absoluto de mulheres no mercado de trabalho no país. Entreo período de 1992 a 2002, a população economicamente ativa feminina evolui de 28 milhões para 36,5 milhões $^{16}$. Entretanto, apesar dos inegáveis avanços, as mulheres estão longe de atingir as taxas masculinas. De acordo com a Pesquisa Mensal de Emprego (PME) realizada pelo Instituto Brasileiro de Geografia e Estatística (IBGE) no mês de dezembro de $2007^{20}$, os homens continuam a re presentar a maioria da população economicamente ativa (54,6\%). A esse respeito, os estudos revelam que desde os anos 1990 verifica-se maior taxa de desemprego entre as mulheres quando comparada com os homens ${ }^{19}$. N esse sentido, segundo dados recentes do Instituto de Pesquisa Econômica A plicada (I pea) provenientes da pesquisa "Demanda e perfil dos trabalhadores formais no Brasil em 2007"21, a maior oferta de trabalho no setor formal no ano de 2007 foi para indivíduos do sexo masculino (63\%). Para cada trêsvagasnão preenchidas no período, duas eram para homens. Acredita-se que o aumento do desemprego no grupo feminino ocorre em razão da maior competitividade nos setores em que antes prevalecia a presença feminina, tal como 0 setor de "serviços pessoais", que vem sendo cada vez mais ocupado pelos homens. Inclui os serviços domésticos, domiciliares, confecção de vestuário e atividades ligadas à higiene pessoal ${ }^{19}$. Conforme têm apontado várias pesquisas, as mulheres estão sobrerrepresentadas nas ocupações caracterizadas por maior precariedade $\mathrm{e}^{22-25}$. A análiseacerca da empregabilidade feminina no Brasil realizada por Lavinas ${ }^{18}$ permitiu observar que o perfil de ocupações do grupo é bastante precário. As mulheres brasileiras têm assumido majoritariamente atividades de baixa qualificação profissional, compreendendo as ocupações no setor doméstico (diaristas, cozinheiras); de escritório (secretária, atendente); no setor público (saúde e ensino); no comércio e em serviços comunitários (sem remuneração). Tais ocupações tendem a impor longas jornadas de trabaIho, vínculos informais ( por conta própria e sem seguridade trabalhista) e diferenças salariais importantes quando comparadas com atividades semelhantes realizadas pel os homens. 0 hiato de renda entre os sexos é de cerca de $R \$ 250,00 \mathrm{em}$ média, como mostram Lavinas et al. ${ }^{19}$.

Fora da esfera do mercado de trabalho compreendendo o universo social e familiar, observase que as mulheres têm sofrido o impacto das transformações estruturais verificadas nas últimas décadas no que diz respeito à composição das famílias brasileiras. 0 maior número de divórcios e separações têm reordenado os arranjos familiares. Dessa forma, cresce o número de domicílios do tipo "mulher sozinha com filhos"17. A chefia dasfamílias brasileirasnosúltimos dez anos sofreu grandes mudanças. Segundo censo realizado pelo IBGE ${ }^{23}$, um em cada quatro domicílios no Brasil é chefiado por mulheres. De fato, a participação das mulheres como chefes de família no período aumentou cerca de $35 \%$, passando de 
22,9\% em 1995 para 30,6\% em 20055. Com relação aos rendimentos, observa-se que o poder aquisitivo dosdomicílios cai sensivelmenteno caso de mulheres chefes de família com filhos menores $^{24}$. Em 2002, o rendimento domiciliar mensal das chefes de família mostrava-seinferior aos dos chefes homens: $36 \%$ delase $28 \%$ delestinham renda de até dois salários mínimos ${ }^{24}$. N essa direção, famílias chefiadas por mulheres são mais vulneráveis ao estado de pobreza no Brasil ${ }^{22}$. Foi o que constataram em seu trabalho Costa et al. ${ }^{25}$. Os autores confirmaram a existência de uma sobrerrepresentação na pobreza de famílias do tipo "mulher sem cônjuge" e com filhos. O perfil dos núcleos chefiados por mulheres é representado por famílias sem cônjuge, com filhos menores e idosas sozinhas. Apesar das mudanças nos arranjos familiares brasileiros, a responsabilidade nos afazeres domésticos ainda é predominantemente das mulheres. Entre as mulheres ocupadas, 92\% delas declaram cuidar de afazeres domésticos. Entre 1995 e 2005, observou-se um tímido aumento da participação dos homens nos afazeres domésticos, mas ainda longe de se afirmar uma divisão de tarefas igualitárias. Em mé dia, as mulheres gastam 25,2 horas semanais nos afazeres domésticos contra 9,8 horas que são gastas na mesma atividade pelo grupo masculino ${ }^{5}$.

Outras características como raça e nível educacional também são importantes na configuração das situações de vulnerabilidade social. Segundo o relatório do Núcleo de Estudos de Políticas Públicas da U niversidade Estadual de Campinas (Nepp/Unicamp) ${ }^{26}$, os chefes de família pretos ou pardos representam $57 \%$ dos domicílios pobres urbanos do país, e dois terços dos chefes de família pobres são analfabetos ou apresentam apenas três anos de escolaridade. Nesse aspecto, observa-se que as mulheres chefes do domicílio em sua maioria são pretas ou pardas, exceto para o Sul e alguns estados do Sudeste ${ }^{24}$. Importante ressaltar que as trabalhadoras negras são mais discriminadas. Em 2002, do total de mulheres empregadas, $63 \%$ eram brancas e $37 \%$ negras $^{16}$. Bruschini et al. ${ }^{16}$ sintetizam o perfil de trabalho e renda das mulheres hoje no Brasil: as mulheres ganham salários inferiores aos dos homens, em quase todas as ocupações, têm sido devastadoramente afetadas pelo desemprego, são mai oria no mercado informal, nas ocupações pre cárias e sem remuneração. Além disso, recai sobre elas grande parte das tarefas domésticas.

\section{Dieta e atividade física}

A pauperização das condições de vida das mulheres brasileiras parece refletir negativamente no padrão de alimentação e de atividadefísica do grupo e, consequentemente, na ascensão da obesidade. Desigualdades sociais têm imposto um padrão de alimentação insuficiente do ponto de vista nutricional. A reduzida margem de escolha na sel eção dos itens de baixa densidade energética, tais como vegetais e frutas, impõe ao grupo a adesão deestratégias de consumo alimentar através da escolha de alimentos mais densos e baratos como meio de combate à fome e à escassez, ameaças permanentes no cotidiano das classes populares ${ }^{2,6}$.

Levy-Costa et al. ${ }^{27}$ verificaram a partir dos resultados da POF (2002-2003) características negativas na dieta da população brasileira no que se refere ao excessivo consumo de açúcar, sobretudo na baixa renda. Observou-se nesta pesquisa um consumo 50\% menor de açúcar nas classes de maior rendimento, quando comparada com as demais classes de renda. N esta mesma direção, Ferreira e M agal hães ${ }^{6}$ verificaram o excessivo consumo de açúcar combinado ao café em mulheres pobres e obesas de uma favela carioca. Aguirré28 também verificou esse padrão de consumo em seu trabal ho com as mulheres obesas argentinas. A autora destaca ainda a questão da desvalorização social feminina e suas repercussões no padrão de alimentação do grupo. Segundo a autora, na distribuição intrafamiliar de alimentos, as mulheres omitem ou sacrificam sua dieta em favor dos demais familiares. Aguirré ${ }^{28}$ verificou que as mulheres obesas argentinas direcionavam os alimentos de melhor qualidade nutricional para os maridos e filhos. N esse aspecto, Wolf ${ }^{29}$ salienta que ao longo de toda a história da humanidade, em épocas de escassez alimentar, as mulheres foram as mais atingidas pela subalimentação. Para a autora, a autoexclusão das mulheres encobre a ideia de que os homens são os provedores e os membros mais importantes da estrutura social.

No entanto, torna-se importante sinalizar que, além das desigualdades de acesso a ração alimentar digna, os aspectos de natureza cultural e simbólica também demonstram ser elementos que interagem na sel eção de alimentos e consequentementeno padrão alimentar das mulheres. A alimentação como um ato social se reveste de significadose, portanto, envolve um universo de escolhas, hábitos e preferências alimentares. No que diz respei to ao padrão alimentar brasileiro, 
podemos dizer que, embora o país apresenteuma enorme diversidade gastronômica, reflexo da miscigenação dos diferentes povos que fizeram parte de sua história, al guns hábitos al imentares assumiram destaque aqui. É o caso do consumo do açúcar e das gorduras. A difusão do açúcar foi trazida pelos exploradores portugueses $e$ ampliou-se através do cultivo da cana-de-açúcar, propiciando dessa maneira o tradicionalismo e o gosto culinário para o doce no país. Dessa forma, o paladar nacional para o açúcar foi sendo construído ${ }^{30}$. A garapa (caldo da cana) ea rapadura, por exemplo, serviam dealimento para os escravos. M ais adiante, nas classes populares uma variedade de doces foi sendo difundida, entre eles os doces de frutas, assim como o uso do açúcar combinado à infusão do café. A gordura, por sua vez, foi incorporada à cultura alimentar do país, sobretudo com a criação de suínos pelos bandeirantes. A partir deles, obtinham a carne fresca; a gordura para a realização de frituras e refogados; o toucinho que conferia gosto ao feijão eos embutidos ${ }^{30}$. Dados recentes sobreo consumo alimentar dos brasileiros revelaram o incremento do consumo de gorduras em geral, especialmente a gordura saturada e o colesterol. E ainda um excessivo consumo de açúcares erefrigerantes ${ }^{4,31}$. Nesse sentido, o padrão alimentar observado entre os grupos sociais encontrase vinculado a um conjunto de valores, crenças e hábitos historicamente construídos e que não podem ser ignorados.

Paralelamenteàs limitações de ordem material, também repercute de maneira negativa na adesão a prática de atividade física de lazer, estratégia fundamental para a prevenção e o controle da obesidade. 0 aspecto financeiro associado à falta de locais públicos para tal fim e a insegurança, sobretudo decorrenteda violência, são fatoresque impossibilitam aos grupos mais desfavorecidos a prática regular deexercíciosfísicos. D eacordo com Sobal ${ }^{15}$, diferentemente da baixa renda, os segmentos das classes mais abastadas dispõem de condições financeiras quelhes permitem a adesão à prática de atividades físicas voluntárias. $\mathrm{Na}$ medida em que tais grupos normalmente assumem ocupações de prestígio e usufruem de maior flexibilidade de horários e autonomia, existiria, portanto, uma tendência maior para a incorporação de tais comportamentos.

A esse respeito, Aguirré28 pontua que no caso da população feminina existe menor disposição e tempo para a prática de atividade física em razão da dupla jornada de trabalho (incluindo os afazeres domésticos) realizada pelo grupo, eain- da uma média de menos duas horas de sono quando comparado com os homens. Este fato justificaria a menor adesão à prática de atividade física pelas mulheres. Pesquisas nacionai ${ }^{32,33}$ mais recentes têm constatado a continuidade de model os familiares tradicionais com a permanência das mulheres na responsabilidade pelos serviços domésticos e os cuidados com os filhos e demais parentes. As mulheres executam majoritariamente as atividades domésticas (79\%) em comparação com os homens (29\%). Este perfil provoca uma sobrecarga de trabalho para o grupo feminino ${ }^{24}$. Segundo a Pesquisa sobre Padrões de Vida ${ }^{32}$ realizada pelo IBGE e o Banco Mundial, os afazeres domésticos estão entre as atividades que mais consomem tempo, com média semanal de trinta horas, variando segundo sexos: 36 horas para as mulheres e 14 horas para os homens. O bserva-se ainda que as mulheres pretas e pardas que residem na Região Nordeste despendem mais horas do que as mulheres brancas moradoras da Região Sudeste, revelando as desigualdades raciais e regionai $s^{31}$. Salles-Costa et al. ${ }^{33}$ verificaram em sua investigação que as muIheres praticavam significativamente menos atividades físicas delazer do queos homens. Dentre as justificativas para esse perfil, eles apontaram a questão da dupla jornada de trabalho das muIheres que, de acordo com os autores, contribui para a limitação do tempo destinado ao lazer. No entanto, o dispêndio dessas atividades tem sido pouco estudado. É possível que os afazeres domésticos apresentem menor demanda energética tendo em vista 0 acesso cada vez maior de equipamentos e bens duráveis $s^{5}$ advindos do processo de modernização.

\section{O simbólico e o cultural}

Elementos simbólicos relacionados à valorização do corpo obeso por parte das mulheres pobres também são evidenciados em algumas investigações. N esses trabal hos, verifica-se que o corpo, muitas vezes, pode expressar a condição de classe ${ }^{14}$. Os estudos têm demonstrado que 0 corpo obeso feminino pode estar vinculado a estereótipos deforça, erotismo esuficiência alimentar. No Brasil, o estudo de Zaluar ${ }^{34}$ revelou que para as mulheres das classes populares a obesidade era por vezes valorizada como elemento de força e poder. Silva ${ }^{35}$, por sua vez, verificou em seu estudo com mulheres obesas de baixa renda no Rio de Janeiro que a obesidade era um atributo sexual importanteno grupo. 0 corpo erótico e sensual era representado pelas formas arredon- 
dadas das mulheres. Segundo Bourdieu ${ }^{36}$, a sociedade imprime ao corpo princípios de divisão social e de oposição que são utilizados como forma de justificar a distinção de classe. N esse sentido, o corpo obeso das mulheres pobres seria uma maneira de diferenciação social ao corpo magro e esbelto das mulheres burguesas.

Para Boltanski ${ }^{14}$, nas classes populares a atenção prestada ao corpo pode ser menos frequente. Particularmente nesses grupos, o uso do corpo pode compreender uma visão mais utilitária, fruto da importância da força física nas ocupações desempenhadas. Nessa perspectiva, para muitas mulheres das classes populares o corpo pode se apresentar como condição para a produção do trabalho. No cotidiano de luta pela sobrevivência diária e dupla jornada de trabaIho, o corpo tende a não ser percebido em toda a sua plenitude ${ }^{6,34,35}$. No entanto, valeressaltar que os estereótipos de corpo são construídos e reconstruídos nos diferentes contextos sociais. N essa direção, observa-se na contemporaneidade a valorização do corpo magro com impacto negativo no grupo feminino, sobretudo nas muIheres joven $s^{37,38}$. 0 corpo magro se reveste hoje deconotações simbólicas de felicidade, prestígio, sucesso pessoal, status, autocontrolee autodisciplina ${ }^{39,40}$. O corpo nas sociedades modernas transforma-se em um objeto ameaçador que deveser vigiado ereduzido permanentemente ${ }^{40,41}$. N esseaspecto, para Bourdieu ${ }^{42}$, as mulheres existem para o ol har dos outros [...] Incessantemente sob o olhar dos outros, elas se vêem obrigadas a experimentar constantemente a distância entre 0 corpo real, a que estão presas, e o corpo ideal, do qual procuram infatigavelmente se aproximar reflexo, segundo o autor, da dominação masculina que fragiliza as mulheres e as torna constantemente inseguras edependentes.

De fato, é notório que atualmente o corpo magro tem sido valorizado e imposto pela mídia com impacto, sobretudo nas classes média e alta de renda. $M$ as também atinge as classes populares, em quese verifica a admiração por modelose atrizes de tel evisão que apresentam esses estereótipos de corpo. Interessantenotar que, contrariamente, existe por parte das camadas socialmente abastadas a vinculação do corpo "gordo" a pessoas que realizam funções mais modestas,como as cozinheiras, revelando que os estereótipos estão presentes, demarcando muitas vezes a condição social6,42. Dessa maneira, novos estudos sobre o tema se fazem necessários.

Vale salientar, ainda, a questão da discriminação e do estigma ao indivíduo obeso. A valori- zação do corpo magro e a obsessão pela magreza trazem como consequência "a rejeição quase maníaca da obesidade" 43 . A gordura passa a associar-se no imaginário coletivo com a ideia de falta de saúde, desleixo, preguiça, falta de controle, falência moral e pobreza ${ }^{39,43}$. A obesidade torna-se uma "deformidade física (e também moral) não sendo tolerada socialmente" ${ }^{44}$.

\section{O peso do emocional}

Fatores emocionais também podem estar relacionados à prevalência de obesidade entre muIheres pobres ${ }^{6,34,35}$. O sdilemas impostos pela vida em meio à pobreza, a fragilidade das redes de apoio social, a responsabilidade pela gerência e pelo sustento financeiro da casa e ainda os cuidados com os filhos podem ser elementos presentes no estilo de vida do grupo. N esse aspecto, segundo Gerhardt ${ }^{45}$, a vida dessas mulheres revela-se penosa, especialmenteem razão do papel central do grupo no gerenciamento do cotidiano das famílias pobres. N essas ocasiões, 0 alimento é o elemento de conforto que ameniza um contexto deadversidades. M ais do quesaciar a fome, o alimento supre carências e ameniza angústias de uma vida sofrida.

Orbach $^{46}$ refere-se ainda ao que denominou de "fome emocional". Diferente da necessidade biológica de saciar a sensação física ocasionada pela falta de alimento, a "fome emocional" diz respeito à utilização da comida para apaziguar sentimentos. Para a autora, os sentimentos são muito parecidos com a comida [...] e se permite vivenciá-lo, ele irá satisfazê $10^{46}$. A autora alerta também para o fato de que muitas vezes a própria sensação de fome amedronta determinados indivíduos, principalmente quando tiveram experiências indesejáveis no passado, como por exemplo quando não dispunham de comida suficiente na infância. Por essa razão, muitas pessoas comem antes que possam sentir fome.

\section{Conclusões}

A partir do exposto, é possível constatar a complexa teia que envolve a dinâmica da obesidade feminina na pobreza. N esse sentido, preocupamnos especial menteas desigual dades no acesso aos principais recursos relacionados à prevenção e ao controle da obesidade na população pobre feminina no Brasil e suas repercussões futuras nesse grupo em particular. Esse cenário aponta para a necessidade da criação deações direciona- 
das à população feminina tendo em vista a maior predisposição biológica do grupo ao acúmulo de gordura corporal. Dessa forma, a assistêncianutricional eas atividades educati vas em saúde se revelam como estratégias úteis, especialmente para o grupo de gestantes e puérperas. $\mathrm{A}$ gravidez e o pós- parto têm demonstrado ser momentos biológicos positivos para o ganho depeso e devem ser valorizados nas atividades de prevenção e controle da obesidade.

0 papel das mulheres como gerenciadoras dos lares as torna agentes multiplicadoras das ações de preven ção da obesi dade e de promoção da saúde. N esse sentido, faz-se necessário subsidiar ações factíveis que possibilitem ao grupo a adesão a estilos de vida mais favoráveis a sua saúde e a de sua família. N esse aspecto, as políticas públicas de geração de emprego e renda, de inclusão social, educação e igual dade no mercado de trabal ho entre os gêneros (no que se refere ao acesso, a postos de trabalho, a remuneração e ascensão) nos parecem caminhos mais promissores para o enfrentamento da obesidade entre mulheres pobres no país.

\section{Colaboradores}

VA Ferreira trabalhou na elaboração, na redação e na revisão do artigo; $R$ M agalhães, na orientação da pesquisa, na elaboração e na revisão.

\section{Referências}

1. World Health Organization (WHO). O besity: preventing and managing the global epidemic. Geneva: WHO; 2000.

2. Peña M, Bacallao J, organizadores. La obesidad en la pobreza: un nuevo reto para la salud publica. Washington: Opas; 2000.

3. Sobal J, Stunkard AJ. Socioeconomic status and obesity: a review on the literature. Psychol Bull 1989; 105(Pt.2):260-275.

4. Instituto Brasileiro de Geografia e Estatística (IBGE). Pesquisa de orçamentos familiares 2002-2003: análise da disponibilidade domiciliar de alimentos e do estado nutricional no Brasil. Rio de Janeiro: IBGE; 2004.

5. Instituto Brasileiro de Geografia e Estatística. Pesquisa Nacional de Amostra Domiciliar (PNAD). [CD-ROM]. Rio de Janeiro: IBGE; 2006.

6. Ferreira VA, Magalhães, R. O besidade e pobreza: 0 aparente paradoxo. Um estudo com mulheres da Favela da Rocinha, Rio de Janeiro, Brasil. Cad Saude Publica 2005; 21(Pt.6):1792-1800.

7. Gibson RS. Principles of nutritional assessment. New York: Oxford University Press; 1990.

8. Kac G, Velasquez-M elendez G, Valente JG. Menarca, gravidez precoce e obesidade em mulheres brasileiras selecionadas em um centro de saúde de Belo Horizonte, Minas Gerais, Brasil. Cad Saude Publica 2003; 19(Supl.1):S111-S118.

9. Lins APM. Fatores associados ao sobrepeso em muIheres de 20 a 59 anos no município do Rio de Janeiro [dissertação]. Rio de Janeiro: Instituto Fernandes Figueira, Fundação O swaldo Cruz; 1999.

10. Sawaya AL, Roberts $S$. Stunting and future risk of obesity: principal physiological mechanisms. Cad Saude Publica 2003; 19(Supl.1):S21-S28.

11. Schroeder DG, Martorell R. Deficiencia del crecimiento fetal e infantil, y obesidad y enfermedad crónica en la edad adulta: importancia para America Latina. In: Peña M, Bacallao J, organizadores. La obesidad en la pobreza: un nuevo reto para la Salud Publica. Washington: Opas; 2000. p. 111-124. 
12. M onteiro CA, Conde WL, Castro IRR. A tendência cambiante da relação entre escolaridade e risco de obesidade no Brasil (1975-1997). Cad Saude Publica 2003; 19(Supl.1):S67-S75.

13. Kac G, Velasquez-M elendez G, Coelho MASC. Fatores associados à obesidade abdominal em muIheres em idade reprodutiva. Rev Saude Publica 2001; 35(Pt.1):46-51.

14. Boltanski L. As classes sociais e o corpo. Rio de Janeiro: Edições Graal; 1979.

15. Sobal J. Obesity and socioeconomic status: a framework for examining relationship between physical and social variables. Medical Anthropology 1991; 13(Pt.3):231-247.

16. Bruschini C, Lombardi MR, Unbehaum S. TrabaIho, renda e políticas sociais: avanços e desafios. In: Fundação Carlos Chagas (FCC). 0 progresso das mulheres no Brasil. Brasília: Fundação Carlos Chagas; 2006. p. 60-101.[livro na Internet] [acessado 2006 mar 13]. Disponível em: http://www.fcc.org.br

17. M edeiros M, Osório R. M udanças nas famílias brasileiras: a composição dos arranjos domiciliares entre 1978 e 1998. Brasília: Ipea; 2002. (Texto para Discussão, no 886).

18. Lavinas L. Empregabilidade no Brasil: inflexões de gênero e diferenciais femininos. Rio de Janeiro: I pea; 2001. (Texto para Discussão, no 826).

19. Lavinas L, Amaral MR, Barros F. Evolução do desemprego feminino nas áreas metropolitanas. Rio de Janeiro: I pea; 2000. (Texto para Discussão, no 756 ).

20. Instituto Brasileiro de Geografia e Estatística (IBGE). Pesquisa mensal de emprego. [site na Internet] 2007. [acessado 2008 mar 18]. Disponível em: http: // www.ibge.gov.br

21. Pochmann M, Campos A, Amorim R. Demanda e perfil dos trabalhadores formais no Brasil em 2007. Brasília: I pea; 2007.

22. Instituto de Pesquisa Econômica Aplicada (I pea). O Brasil no fim do século: desafios e propostas para ação governamental. Rio de Janeiro: I pea; 1994.

23. Instituto Brasileiro de Geografia e Estatística (IBGE). Censo demográfico 2000. [acessado 2006 mar 14]. Disponível em: http://www.ibge.gov.br

24. Fundação Carlos Chagas (FCC). Banco de dados sobre o trabalho da mulher. São Paulo: FCC; 11998. [documento na Internet] [acessado 2006 mar 13]. Disponível em: http:// www.fcc.org.br

25. Costa JS, Pinheiro L, Medeiros M, Queiroz C. A face feminina da pobreza: sobre representações e feminização da pobreza no Brasil. Brasília: Ipea; 2005. (Texto para Discussão, no 1.137).

26. Universidade Estadual de Campinas (Unicamp). Núcleo de Estudos de Políticas Públicas. Família e pobreza [relatório final]. Convênio Fecamp-Ipea. Campinas: Unicamp; 1992.

27. Levy-Costa RB, Sichieri R, Pontes NS, Monteiro CA. Disponibilidade domiciliar de alimentos no Brasil: distribuição e evolução (1974-2003). Rev Saude Publica 2005; 3(Pt.4):530-540.

28. Aguirré P. Aspectos socioantropológicos de la obesidad en la pobreza. In: Peña M, Bacallao J, organizadores. La obesidad en la pobreza: un nuevo reto para la Salud pPblica. Washington: O pas; 2000. p. 13-25.

29. Wolf N. O mito da beleza: como as imagens de beleza são usadas contra as mulheres. Rio de Janeiro: Rocco; 1992
30. Zarvos N, Ditadi CAS. Multissabores: a formação da gastronomia brasileira. Rio de Janeiro: Senac; 2000.

31. Galeazzi MAM, Domene SMA, Schieri R. Estudo multicêntrico sobre consumo alimentar. Brasília: Ministério da Saúde; 1997.

32. Instituto Brasileiro de Geografia e Estatística. Pesquisa sobre padrões de vida 1996/1997. [CD-ROM]. Rio de Janeiro: IBGE; 1999.

33. Salles-Costa R, Heilborn ML, Werneck GL, Faerstein $E$, Lopes CS. Gênero e prática de atividade física de lazer. Cad Saude Publica 2003; 19(Supl.2): S325-S333.

34. Zaluar A. A máquina e a revolta: as organizações populares e o significado da pobreza. São Paulo: Brasiliense; 1985.

35. Silva DO. 0 fiel da balança na história do corpo obeso em mulheres de baixa renda [dissertação]. Rio de Janeiro: Escola Nacional de Saúde Pública Sergio Arouca, Fiocruz; 1997.

36. Bourdieu P. A economia das trocas simbólicas. São Paulo: Perspectiva; 1992.

37. Bosi M LM, Raggio R, Costa M, Morgado C. Autopercepção da imagem corporal entre estudantes de nutrição. Jornal Brasileiro de Psiquiatria 2006; 55(1): 34-40.

38. Andrade A, Bosi M LM. Mídia e subjetividade: impacto no comportamento alimentar feminino. Rev Nutr 2003; 16(1):117-125.

39. Vasconcelos NA, Sudo I, Sudo N. Um peso na alma: o corpo gordo e a mídia. Rev M al-estar e Subjetividade 2004; 4(1):65-93.

40. Goldenberg M. O corpo como capital: estudos sobre gênero, sexualidade e moda na cultura brasileira. São Paulo: Estação das Letras e Cores; 2007.

41. Baudrillard J. A sociedade de consumo. Rio de Janeiro: Edições 70; 1995.

42. Bourdieu P. Dominação masculina. Rio de Janeiro: Bertrand Brasil; 2005.

43. Fischler CC. Obeso benigno, obeso maligno. In: Sant'Anna DB, organizador. Políticas do corpo: elementos para uma história das práticas corporais. São Paulo: Estação Liberdade; 1989. p. 69-80.

44. Santos LAS. 0 corpo, o comer e a comida: um estudo sobre as práticas corporais e alimentares cotidianas a partir da cidade de Salvador - Bahia [tese]. São PauIo: Pontifícia Universidade Católica de São Paulo; 2006.

45. Gerhardt TE. Situações de vida, pobreza e saúde: estratégias alimentares e práticas sociais no meio urbano. Cien Saude Colet 2003; 8(3):713-726.

46. Orbach S. Sobre a comida: reaprenda a comer e mude sua vida. Rio de Janeiro: Record; 2003.

Artigo apresentado em 05/03/2008

Aprovado em 10/02/2009

Versão final aprovada em 28/02/2009 